\title{
Guideline for multiple sclerosis treatment in Brazil: Consensus from the Neuroimmunology Scientific Department of the Brazilian Academy of Neurology
}

Orientações para tratamento da esclerose múltipla no Brasil: Consenso do Departamento Científico de Neuroimunologia da Academia Brasileira de Neurologia

Elizabeth Regina Comini-Frota ${ }^{1,4}$, Cláudia C. F. Vasconcelos ${ }^{2,4}$, Maria Fernanda Mendes 3,4 , on behalf of DCNI study group

\begin{abstract}
Multiple sclerosis has become an ever-increasing challenge to neurologists. With the release of the latest medications on the market, Brazilian neurologists feel divided between following their patients' evolution in accordance with the strict rules established by the Brazilian Ministry of Health regarding drug distribution, or following disease progression and worsening in accordance with the evidence in the literature. Therefore, a systematic review of the main published treatment guidelines was conducted and an escalating therapy proposed for guiding multiple sclerosis patient treatment in Brazil.
\end{abstract}

Keywords: multiple sclerosis; Consensus, treatment.

\section{RESUMO}

A esclerose múltipla vem se tornando um desafio crescente para os neurologistas. Com o lançamento de novos medicamentos no mercado, os neurologistas brasileiros se encontram divididos entre, apesar da evolução dos seus pacientes, seguir as regras restritas estabelecidas pelo Ministério da Saúde para distribuição de medicamentos, ou ao contrário, considerar a progressão e piora da doença, em concordância com as evidências da literatura. Devido a este impasse foi realizada uma revisão sistemática sobre as principais orientações de tratamento publicadas e foi proposto um escalonamento terapêutico para orientar o tratamento dos pacientes com esclerose múltipla no Brasil.

Palavras-chave: esclerose múltipla; Consenso, tratamento.

Multiple sclerosis (MS) is a pleomorphic disease with respect to its immunopathological, genetic, demographic, clinical and therapeutic profile variability. This is probably the reason that this condition is so challenging for neurologists. So far, interactions between different genes and several environmental factors that are not yet clearly defined seem to be the main reason for phenotypic variations within MS and different therapeutic responses to drugs ${ }^{1}$.
Given the complexity of the symptoms of MS and its clinical course, neurologists face an important challenge in relation to the maxim primum non nocere, i.e. above all, do no harm $^{1}$. In clinical practice, treating MS without causing harm may have several meanings:

1) to begin with, modify and withdraw the treatment at the right moment, thus avoiding worsening of the disease and negative effects on the patient's quality of life;

\footnotetext{
'Universidade José do Rosário Vellano, UNIFENAS, Belo Horizonte MG, Brasil;

2Universidade Federal do Estado do Rio de Janeiro, Departamento de Neurologia, Rio de Janeiro RJ, Brasil;

${ }^{3}$ Santa Casa de São Paulo, Departamento de Neurologia, São Paulo SP, Brasil;

${ }^{4}$ Academia Brasileira de Neurologia, Departamento Científico de Neuroimunologia (DCNI), São Paulo SP, Brasil.

DCNI Study Group collaborators: Kaimen-Maciel DR, Adoni T, Moreira M, Pimentel MAV, Grzesiuk AK, Brum DG, Gonçalves MVM, Finkelsztejn A, Damasceno A, Santos ALM, Teixeira AL. Neto APG, Silva DJ, Diniz D, Correa EC, Tosta ED, Figueira FF, Cabeça HLA, Becker J, D’Almeida JAC, Ferreira MLB, Parolin MKF, Papaiz-Alvarenga R, Melo RBS, Morales RR, Alves-Leon SV, Machado SCN, Ribeiro TCGJ, Winckler TCD, Junqueira TM.

Correspondence: Elizabeth Regina Comini-Frota; Universidade José do Rosário Vellano (UNIFENAS-BH), Rua Líbano 66 Belo Horizonte, MG, Brazil, CEP 31710-030..E-mail: elizabeth.frota@unifenas.br, elizcomini@gmail.com.

Conflict of interest: There is no conflict of interest to declare.

Received 10 September 2016; Accepted 22 September 2016.
} 
2) to choose the best possible treatment, making the choice individually for different patients and for different times of disease evolution in each patient;

3) to weigh up the risks and benefits of each treatment, and to not treat beyond, or short of, what is necessary;

4) to strictly follow the recommendations for each drug, thus minimizing adverse events;

5) to respect the patient's tolerance to adverse events and to the proposed treatment schedule.

In order to surmount this challenge, neurologists need to be supported by evidence from the literature, by their own experience and by good doctor-patient relationships. The increase in the number of disease-modifying drugs has substantially changed the approach to patients with MS. The worldwide literature shows that treatment guidelines are now aimed at the most appropriate choice among all the presently-available therapeutic options.

Management of MS in Brazil must take into account the recommendations from the Brazilian Ministry of Health², but most of all, it needs to be supported by the evidence from the international literature and from knowledge obtained in clinical practice. With the best possible treatment for patients with MS in mind, neurologists of the Neuroimmunology Scientific Department (DCNI) of the Brazilian Academy of Neurology joined a DCNI study group reviewing the literature on treatments published in the last five years. The recommendations presented here are in accordance with their revision and consensus.

The three generations of disease-modifying drugs that have been developed since 1993 treat the first stage of the disease, when inflammation is predominant $t^{3,4,5,6,7,8,9,10,11,12,13}$. For patients evolving to progressive disease with little (or no) inflammatory activity and predominant degeneration, there is no medication with proven efficacy ${ }^{1}$. Therefore, the objective of MS treatment is to delay reaching the second stage of the disease for as long as possible.

Thus, early recognition of therapeutic failure and disease progression is extremely important. Use of the established parameters to determine whether the patient is responding or not to a given treatment needs to be part of therapeutic management ${ }^{14}$. Switching treatment is a challenge for neurologists in daily practice, with respect to therapy escalation and management of the safety aspects of drugs that are more effective.

Table 1 shows that, over the years, patients included in clinical trials have had ever-lower relapse rates, despite similar average disease duration. Patients now enrolled in phase III trials are more homogeneous, thanks to the knowledge acquired over the last 20 years of clinical and radiological evolution of the disease. The primary and secondary outcomes used in clinical trials have also been modified to meet the demands of regulatory agencies. The levels of evidence comparing the efficacy of medications investigated over a decade ago and of newer drugs are unreliable, since the earlier trials were on patients with a less homogeneous profile, and considered different outcomes ${ }^{15}$. Likewise, regarding safety, the risk of infectious diseases and cancer is now different, and newer drugs that are more efficient come with higher risks. Drugs that are more effective against autoimmunity are inherently likely to affect immune surveillance against infections. Based on the evidence, and always keeping in mind the safety recommendations of a given drug, doctors need to consider the efficacy of a treatment for a given patient, as well as the risks posed by the MS itself.

Several competing factors are present at the time a therapeutic decision is made. There are factors that are inherent to the patient: psychological condition, lifestyle, disease burden, quality of life and culture. There are also socioeconomic factors, and there are matters relating to the doctor that may determine the choice of therapy. These may include clinical experience, along with expectations regarding disease control and the doctor-patient relationship.

In Brazil, the distribution of MS-specific medications follows the protocol from the Ministry of Health, but it is not exempt from regional interpretations. The Clinical Protocol for Therapeutic Recommendations ${ }^{2}$ of the Ministry of Health is based upon bureaucratic rules and pharmacoeconomics. It is, therefore, inflexible. It does not take into account the present advances in knowledge because it does not consider the complexity and individual heterogeneity of the disease and of its treatment. Although the protocol meets the regulatory needs of the State, it restricts the treatment that would be most appropriate for each patient and therefore represents a step backward in MS treatment.

The objective of this guideline is to suggest therapeutic strategies based on level of evidence relating to medications, in accordance with the recommendations from different countries worldwide, to propose a guideline for neurologists who treat MS, and suggest to the Ministry of Healthy a revision of its Clinical Protocol for Therapeutic Recommendations.

\section{METHODS}

This study was a systematic review of guidelines, metaanalysis and therapy escalation. The primary questions were: (a) when to start treatment and what is the most appropriate choice for a drug; (b) switching between medications; (c) level of evidence for the choice of other medications in cases of failure of the first drug; (d) level of evidence for the choice of other medications in cases of failure of the second drug; and (e) most appropriate escalation therapy.

The search strategy in the PubMed and Cochrane Library databases used the following descriptors: "systematic review and multiple sclerosis", "guidelines and multiple sclerosis", "strategies and multiple sclerosis", "first-line therapy" and "starting treatment and multiple sclerosis". The inclusion criteria were that the papers needed to have been published 


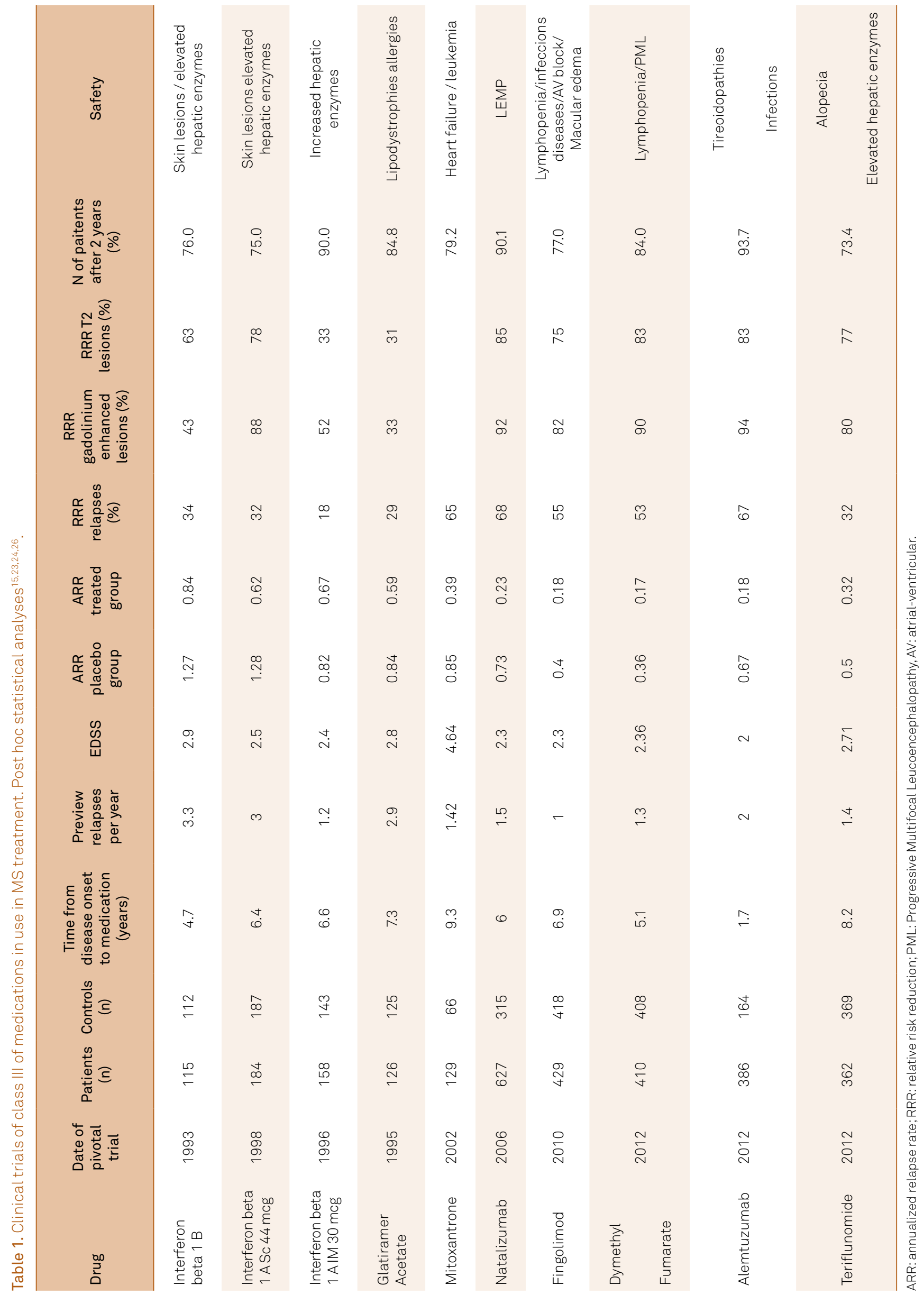


in the English language, from 2012 onwards, and needed to be classified as reviews, meta-analyses, systematic reviews, algorithms or treatment guidelines. Evidences were classified according GRADE criteria ${ }^{15,16,17,18}$.

\section{RESULTS}

There were 244 published papers meeting the strategy descriptors in PubMed, and four papers meeting them in the Cochrane Library database. Seven papers were excluded because the individuals involved were participating from within pharmaceutical companies or were being funded directly by the industry. From the 237 papers, 21 were selected because they fulfilled the following criteria: they included all (or most) medications currently in use; they were not sponsored directly by a pharmaceutical company (or by only one); and they covered different regions. In addition to the papers used in this review, the active search included the initial studies on all the medications in order to prepare Table 1 . The studies selected are listed in Table 2.

\section{When should treatment be started and which medication is most appropriate?}

At the time of the first demyelinating event, while no predictors of unfavorable disease evolution are available, use of injectable immunomodulatory drugs show a high level of evidence for reduction of the relapse rate and lower lesion load on magnetic resonance imaging $(\mathrm{MRI})^{19}$. In addition, there is a high level of evidence of a good safety profile for this treatment. These drugs continue to be the first-line therapy in all guidelines published so far in different countries ${ }^{1,2,3,4,5,6,7,8,9,10,11,12,13,14,15,16,17,18,19,20}$.

Two systematic reviews assessed the results from studies on interferon and glatiramer acetate at the first demyelinating event. Both of them concluded that there was some benefit in using the treatment to delay the second relapse and, therefore, for clinical control of the disease ${ }^{21,22}$.

Interferon beta and glatiramer acetate have similar efficacy, however the different forms of administration and regimen have to be considered according to the personal characteristics, which could promote improved adherence ${ }^{23}$.

Among the oral drugs available, teriflunomide can be used as first-line therapy if there are no formal contraindications for its use (patients who might become pregnant within the short or medium term $)^{13,14,15}$. Teriflunomide presents a high level of evidence regarding control of relapses and lesions on MRI, and its efficacy is considered to be similar to that of the injectable immunomodulatory drugs ${ }^{13}$. Teriflunomide presents risks of adverse events that need to be continuously monitored, such as alterations to liver enzyme levels and lymphopenia. Other effects limit use of this drug, such as telogenous efflux $x^{15,16,17,18,19,20,21,22,23,24}$.
Dimethyl fumarate (DMF) had just been approved for the Brazilian market at the time of this review and guideline being drawn up. The National Health Surveillance Agency approved this medication as a first-line treatment. There is a high level of evidence regarding the efficacy of this drug for controlling relapses and new lesions on $\mathrm{MRI}^{11}$. It has been shown to be more efficient than injection therapies in relation to some outcomes, such as new T2 lesions or new gadolinium enhanced lesions, while its capacity to control disease progression has been found to be comparable to that of glatiramer acetate ${ }^{1,11,15}$. A recent report on two patients with progressive multifocal leukoencephalopathy (PML) associated with persistent lymphopenia raised concerns regarding the safety and pharmacovigilance of this drug ${ }^{25}$. Because the safety profile of this drug is still under observation, its use as a first-line therapy requires caution, or it must be reserved for patients with predictors of unfavorable disease evolution, which are: high lesion burden or high risk of poor outcomes due to frequent relapses or to incomplete recovery from brainstem symptoms ${ }^{14}$.

Patients with predictors of unfavorable disease evolution should be started as soon as possible, even as a first-line therapy, besides DMF, with natalizumab or fingolimod, according to the patient's personal characteristics, John Cunningham (JC) virus index, tolerability and drug adverse events profile.

\section{Conclusion}

Interferon and glatiramer acetate continue to be good alternatives for use as first-line therapy, given their high safety profile observed over the 20 years they have been on the market. In situations of high lesion burden or high risk of poor outcomes due to frequent relapses or to incomplete recovery from brainstem symptoms, other alternatives should be considered as soon as possible. Dymethyl fumarate, as well natalizumab or fingolimod could be started at any time, even as a first choice, if the patient evaluation detects these predictors. Efficacy and safety data must be weighed up in deciding whether to use these drugs.

\section{When should one injectable immunomodulatory drug be switched to another?}

Two recent reviews compared the efficacy of immunomodulatory drugs with regard to their efficacy in relation to several outcomes ${ }^{23,26}$. The results were conflicting. The first review assessed phase III trials and observational studies comparing different interferons, glatiramer acetate, azathioprine, mitoxantrone and natalizumab ${ }^{26}$. It had concluded that interferons have varying degrees of efficacy and that subcutaneous interferon beta $1 \mathrm{a}$ is the most efficient immunomodulatory drug. On the other hand, it also concluded that after two years, it was not possible to guarantee the efficacy of any of these drugs in relation to any of the outcomes studied. The second review compared interferons as a whole with glatiramer acetate, and concluded that all of 


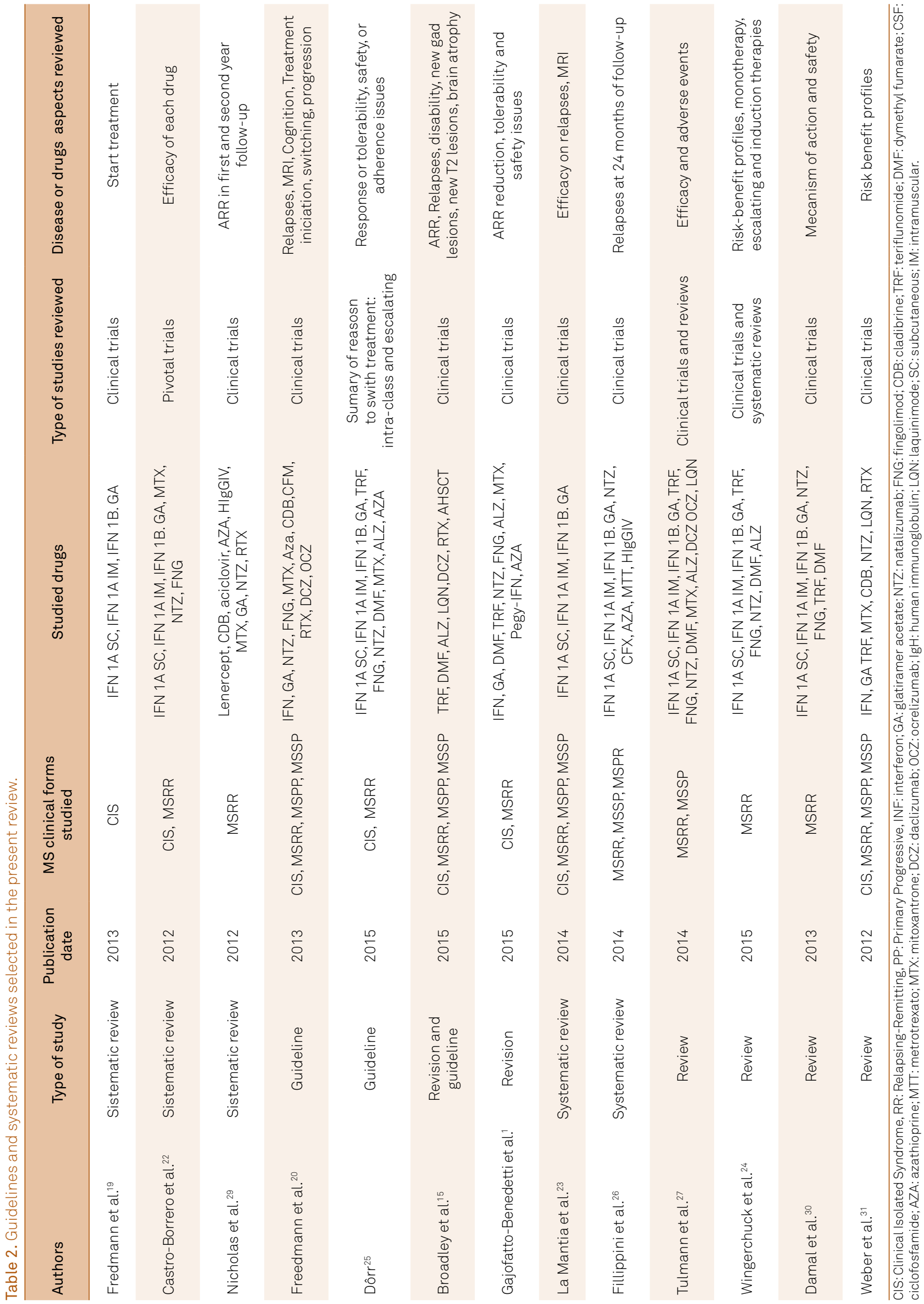


them had similar efficacy ${ }^{23}$. Both of these are respectable reviews in the Cochrane Library, but the choice of studies for inclusion may have affected the results to the point of causing conflicting results ${ }^{1,27}$.

So far, three factors providing high evidence for justifying a switch from one drug to another of the same efficacy have been identified: tolerance, adverse events profile and adherence $^{1,20}$. We do not have the option of assessing neutralizing antibodies against interferons, as is done in other countries.

Patients using interferons, who have intolerable adverse events and have no evidence of disease activity to justify a switch to more efficient drugs with a lower safety profile, can change one first-line therapy for another. They can switch from interferon to glatiramer acetate and vice versa or, as already done in other countries, migrate from interferons or glatiramer acetate to teriflunomide or dimethyl fumarate $^{1,20,25}$. In Brazil, although the latter two options have been approved by the National Health Surveillance Agency for commercialization, they are not yet available free of charge via the Ministry of Health.

Another situation to consider is inadequate adherence. There is no published Brazilian paper showing therapeutic failure due to poor adherence to injectable drugs, but this is a factor to be taken into consideration. For a long time, patients only had the therapeutic option of injectable drugs, sometimes associated with intolerable side effects. A multicenter, multinational and prospective study on adherence to medications showed that women were less adherent than men in countries where the doctor-patient relationship was less valuable ${ }^{28}$. The choice of drug for starting treatment was also relevant, and adherence was better with glatiramer acetate than with interferon ${ }^{28}$. At present, access to oral drugs brings the option of more convenience for patients, particularly in relation to adverse events or poor adherence relating to intramuscular or subcutaneous injections. Considering the lower safety profile associated with oral drugs in relation to injectable drugs, the risks need to be weighed up well when making the decision.

\section{Conclusion}

Migration between drugs of similar efficacy profiles, such as interferon beta and glatiramer acetate, is only recommended in the presence of adverse events or poor adherence. The side effects of new oral drugs must be taken into consideration when switching with the purpose of best adherence.

\section{When should the treatment be changed to a more efficient drug?}

A switch to more efficient drugs needs to be considered in cases of therapeutic failure ${ }^{14,19}$, or if the patient evaluation meets predictors of an unfavorable outcome ${ }^{24,29}$.

The most efficient drugs that have been classically used as second-line therapy in MS management strategies are natalizumab and fingolimod. Natalizumab has shown high levels of evidence of efficacy in controlling the relapse rate and disease progression in all trials in which it was tested, in comparison with both placebo and other drugs ${ }^{9,26}$. It has high efficacy in cases of very active disease, and patients with higher lesion volume and more active lesions were included in the trials ${ }^{9,15,26}$. The treatment regimen is comfortable for the patient, with adverse events that are generally controllable, except for the worrying possibility of PML. The risk of PML is more significant after two years of use of natalizumab ${ }^{24}$. New strategies for minimizing this risk are continually being investigated, and it may soon be possible to assess these strategies ${ }^{24,27,30}$. Use of natalizumab should be recommended in cases of highly active disease, and should be used preferentially in patients who test negative for the JC virus $^{19,20,24,25}$. When the test is positive, the index value needs to be considered and the risks must be discussed between the patient and the doctor, taking into consideration all the risks and benefits of using the medication for a maximum of two years, if the patient has not taken immunossupressants. After two years, natalizumab should be changed to another drug, not because of efficacy escalation but to prevent $\mathrm{PML}^{24}$. If the disease is under control, fingolimod or DMF are the drugs of choice, for patient tolerance, and for some aspects of the disease where these drugs have some equivalent benefits, as can be seen in Table $1^{15}$.

Fingolimod has a comfortable treatment regimen, with one capsule a day. It has a high level of evidence of control over relapses and lesions on MRI, moderate levels of evidence of control over disease progression and low levels of evidence of efficacy with regard to very active disease ${ }^{10,15,24}$. In several treatment protocols, this drug was cited as the second-line choice. However, in many countries, it has been decided to start treatment with fingolimod for patients with factors that predict a worse prognosis, as is done with natalizumab ${ }^{24}$.The adverse events need to be foreseen and actively investigated through laboratory tests. The occurrence of lymphopenia as an adverse effect is frequent, and when it is less than $500 \mathrm{cell} / \mathrm{mm}^{3}$, patients need to be efficiently monitored, and followed-up frequently to reduce the risk of infections. Monitoring for other events, such as macular or cardiovascular abnormalities must be according to drug recommendations.

\section{Conclusion}

Migration from drugs that are considered to be less effective but with more safety options to those that are more effective and with less safety options is recommended whenever therapeutic failure with the originally-prescribed medication occurs.

The decision to use natalizumab or fingolimod should be made after taking into consideration the disease activity and the risks of developing PML and lymphopenia. Therefore, in this consensus we prefer to consider the disease activity and predictors of poor prognosis when making therapeutic 
decisions, rather than considering drugs to be the first or second-line therapies.

When using fingolimod as well as DMF, it is important to consider lymphopenia of less than 500 cells $/ \mathrm{mm}^{3}$ to be a risk factor. Patients should be monitored and, if there is a drop to below 200 cells $/ \mathrm{mm}^{3}$, the drug should be withdrawn immediately. For natalizumab, tests for JC virus should be done every six months and the risks need to be assessed.

\section{Failure of natalizumab and fingolimod}

Alemtuzumab was approved in Brazil in 2015. For patients with very active disease and failure in previous therapies, this drug could be an option ${ }^{12,15,19,24}$. The level of evidence regarding control over relapses, progression and lesion burden on MRI was considered to be moderate. However, the phase III studies were not double blind trials. The level of thyroid disease among patients exposed to the drug was high ${ }^{31,32}$. It is important to observe that patients who were virgin for other treatments and were included in the phase III trial on alemtuzumab presented with a much shorter disease duration and similar number of relapses as in other studies, meaning that they did not yet have a very active disease ${ }^{12}$. Further studies will be useful for assuring the role of this medication. Use of alemtuzumab is recommended in cases of therapeutic failure of other disease-modifying therapies ${ }^{24,30,31}$.

After using medications with moderate to high levels of evidence of control over the disease, autologous transplantation of hematopoietic stem cells is under consideration as a potential treatment option ${ }^{15}$, especially when the use of drugs without evidence is a possibility. Among these drugs are cyclophosphamide and mitoxantrone $e^{8,26}$. The latter was approved by the US Food and Drug Administration in 2002 and presents a high level of evidence of control over relapses, but it has not been widely used due to the risk of cardiovascular and neoplastic diseases. Azathioprine, an inhibitor of purine synthesis, was considered to have an efficacy similar to that of other immunomodulatory drugs, in a 2013 Cochrane review $^{26}$. The results from these analyses require confirmation from other studies.

Other drugs, as daclizumab, ocrelizumab and even rituximab, have not yet been approved in Brazil for treating MS. It is believed that, with the evolution of new therapeutic options, all protocols concerning treatment for MS must be revised regularly.

The escalation of therapy after considering all the evidence presented in this review is summarized in the Figure. The primary goals of treatment are control of disease activity and reducing the risk of disability progression. Prognostic factors and the therapeutic window have to be considered at the time of the choice of medicine. Induction therapy using one of the cited drugs is a matter for another review and is beyond of the aim of this one.

\section{CONCLUSION}

Unfortunately, independent of the pathway followed and the drugs chosen, around ten percent of the patients will progress in their disease, thus accumulating degeneration, with added and irreversible sequelae. There will also be a small percentage of patients, around ten percent, who will respond well to the first therapy prescribed, with optimal

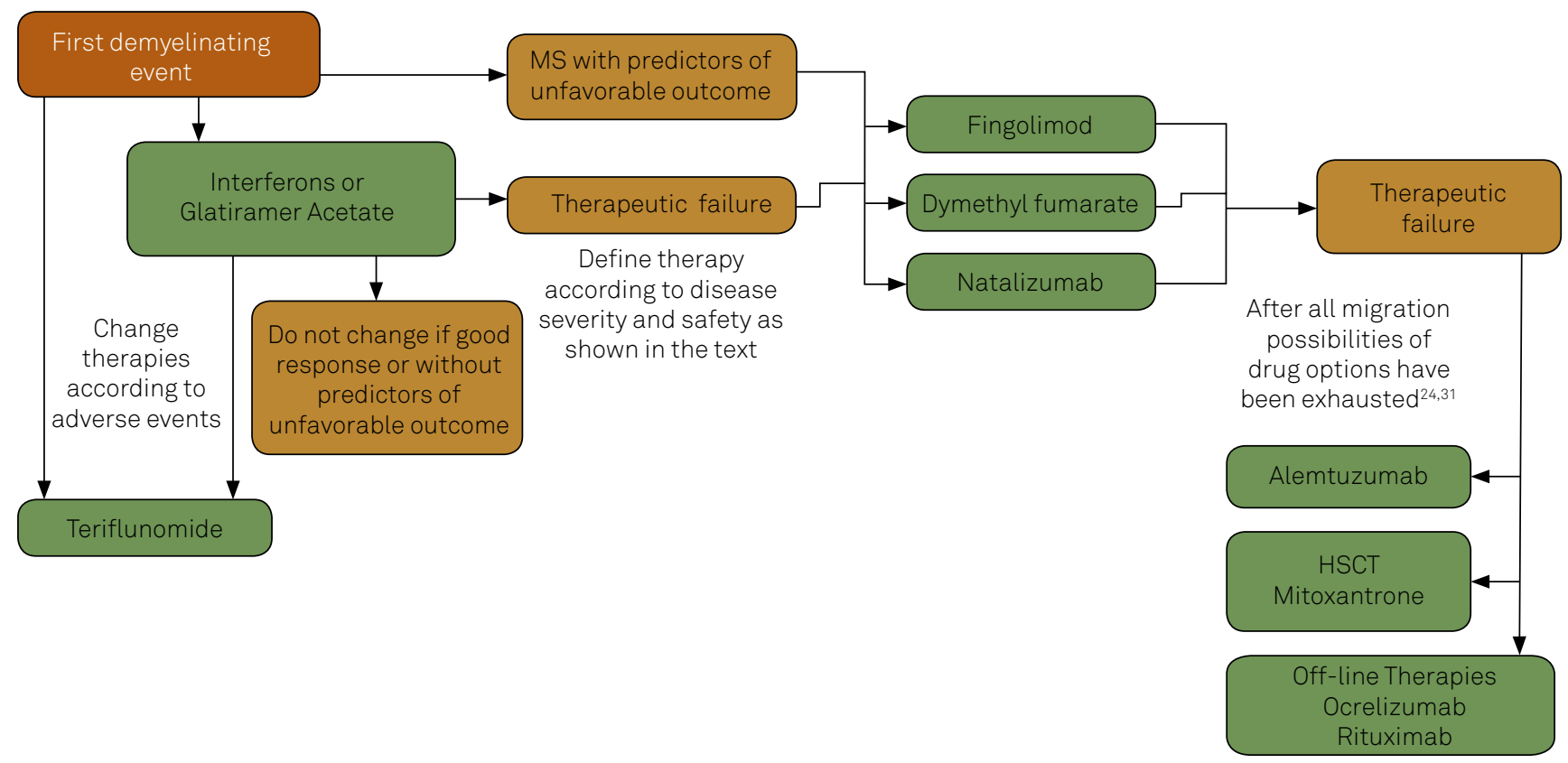

Figure. Recommendation of escalating therapies according to the DCNI Departamento Científico de Neuroimunologia Study Group Consensus. 
control over relapses and lesion burden on $\mathrm{MRI}^{32}$. This seems to occur independently of the use of medications. Between these two extremes, there are many patients who, from the onset of the disease, may benefit from the use of drugs that are more appropriate for their profile and who will depend exclusively upon the perspicacity, attention and common sense of the neurologist. It is expected that this review will help both doctors and their patients.

\section{References}

1. Gajofatto A, Benedetti MD. Treatment strategies for multiple sclerosis: when to start, when to change, when to stop? World J Clin Cases. 2015;3(7):545-55. doi:10.12998/wjcc.v3.i7.545

2. Ministério da Saúde (BR). Portaria No 391, de 5 de maio de 2015. Aprova o Protocolo Clínico e Diretrizes Terapêuticas da Esclerose Múltipla. Diário Oficial União. 6 maio 2015;Seção1:40.

3. Interferon beta- $1 \mathrm{~b}$ is effective in relapsing-remitting multiple sclerosis. I: clinical results of a multicenter, randomized, double-blind, placebo- controlled trial. Neurology 1993;43(4):655-61. doi:10.1212/WNL.43.4.655

4. Paty DW, Li DK. Interferon beta- $1 \mathrm{~b}$ is effective in relapsingremitting multiple sclerosis. II. MRI analysis results of a multicenter, randomized, double-blind, placebo-controlled trial. Neurology. 1993;43(4):662-7. doi:10.1212/WNL.43.4.662

5. Jacobs LD, Cookfair DL, Rudick RA, Herndon RM, Richert JR, Salazar AM et al. Intramuscular interferon beta-1a for disease progression in relapsing multiple sclerosis. Ann Neurol. 1996;39(3):285-94. doi:10.1002/ana.410390304

6. Randomised double-blind placebo-controlled study of interferon beta- 1a in relapsing/remitting multiple sclerosis. Lancet 1998;352(9139):1498-504. doi:10.1016/S0140-6736(98)03334-0

7. Johnson KP, Brooks BR, Cohen JA, Ford CC, Goldstein J, Lisak RP et al. Copolymer 1 reduces relapse rate and improves disability in relapsing-remitting multiple sclerosis: results of a phase III multicenter, double-blind placebo-controlled trial. Neurology. 1995;45(7):1268-76. doi:10.1212/WNL.45.7.1268

8. Hartung HP, Gonsette R, König N, Kwiecinski H, Guseo A, Morrissey SP et al. Mitoxantrone in progressive multiple sclerosis: a placebo-controlled, double-blind, randomised, multicentre trial. Lancet. 2002;360(9350):2018-25. doi:10.1016/S0140-6736(02)12023-X

9. Polman $\mathrm{CH}, \mathrm{O}$ 'Connor PW, Havrdova E, Hutchinson M, Kappos L, Miller DH et al. A randomized, placebo-controlled trial of natalizumab for relapsing multiple sclerosis. N Engl J Med. 2006;354(9):899-910. doi:10.1056/NEJMoa044397

10. Kappos L, Radue EW, O'Connor P, Polman C, Hohlfeld R, Calabresi P et al. A placebo-controlled trial of oral fingolimod in relapsing multiple sclerosis. N Engl J Med. 2010;362(5):387-401. doi:10.1056/NEJMoa0909494

11. Gold R, Kappos L, Arnold DL, Bar-Or A, Giovannoni G, Selmaj Ket al. Placebo-controlled phase 3 study of oral BG-12 for relapsing multiple sclerosis. N Engl J Med. 2012;367(12):1098-107. doi:10.1056/NEJMoa1114287

12. Cohen JA, Coles AJ, Arnold DL, Confavreux C, Fox EJ, Hartung HP et al. Alemtuzumab versus interferon beta 1 a as first-line treatment for patients with relapsing-remitting multiple sclerosis: a randomised controlled phase 3 trial. Lancet. 2012;380(9856):1819-28. doi:10.1016/S0140-6736(12)61769-3

13. O'Connor P, Wolinsky JS, Confavreux C, Comi G, Kappos L, Olsson TP et al. Randomized trial of oral teriflunomide for relapsing multiple sclerosis. N Engl J Med. 2011;365(14):1293-303. doi:10.1056/NEJMoa1014656

14. Sormani MP, Rio J, Tintorè M, Signori A, Li D, Cornelisse $P$ et al. Scoring treatment response in patients with relapsing multiple sclerosis. Mult Scler. 2013;19(5):605-12. doi:10.1177/1352458512460605
15. Broadley SA, Barnett MH, Boggild M, Brew BJ, Butzkueven H, Heard $R$ et al. Therapeutic approaches to disease modifying therapy for multiple sclerosis in adults: an Australian and New Zealand perspective: part 2 new and emerging therapies and their efficacy. J Clin Neurosci. 2014;;21(11):1847-56. doi:10.1016/j.jocn.2014.01.018

16. Balshem H, Helfand M, Schünemann HJ, Oxman AD, Kunz R, Brozek $\mathrm{J}$ et al. GRADE guidelines 3: rating the quality of evidence. $\mathrm{J}$ Clin Epidemiol. 2011;64(4):401-6. doi:10.1016/j.jclinepi.2010.07.015

17. Guyatt G, Oxman AD, Akl EA, Kunz R, Vist G, Brozek J et al. GRADE guidelines: 1. Introdction-GRADE evidence profiles and summary of findings tables. J Clin Epidemiol. 2011;64(4):383-94. doi:10.1016/j.jclinepi.2010.04.026

18. Guyatt GH, Oxman AD, Kunz R, Atkins D, BrozekJ, Vist G et al. GRADE guidelines :2. Framing the question and deciding an important outcomes.J Clin Epidemiol. 2011;64(4):395-400. doi:10.1016/j.jclinepi.2010.09.012

19. Freedman MS, Comi G, De Stefano N, Barkhof F, Polman CH, Uitdehaag BM et al. Moving toward earlier treatment of multiple sclerosis: findings from a decade of clinical trials and implications for clinical practice. Mult Scler Relat Disord. 2014;3(2):147-55. doi:10.1016/j.msard.2013.07.001

20. Freedman MS, Selchen D, Arnold DL, Prat A, Banwell B, Yeung M et al. Treatment optimization in MS: canadian MS Working Group updated recommendations. Can J Neurol Sci. 2013;40(3):307-23. doi:10.1017/S0317167100014244

21. Clerico M, Faggiano F, Palace J, Rice G, Tintorè M, Durelli L.. Recombinant interferon beta or glatiramer acetate for delaying conversion of the first demyelinating event to multiple sclerosis. Cochrane Database Syst Rev. 2008;(2):CD005278. doi:10.1002/14651858.CD005278.pub3

22. Castro-Borrero W, Graves D, Frohman TC, Flores AB, Hardeman P, Logan D et al. Current and emerging therapies in multiple sclerosis: a systematic review. Ther Adv Neurol Disorder. 2012;5(4):205-20. doi:10.1177/1756285612450936

23. La Mantia L, Di Pietrantonj C, Rovaris M, Rigon G, Frau S, Berardo $\mathrm{F}$ et al. Interferons-beta versus glatiramer acetate for relapsing-remitting multiple sclerosis. Cochrane Database Syst Rev. 2014;7:CD009333. doi:10.1002/14651858.CD009333.pub2

24. Wingerchuk DM, Carter JL Multiple sclerosis: current and emerging disease-modifying therapies and treatment strategies. Mayo Clin Proc. 2014;89(2):225-40. doi:10.1016/j.mayocp.2013.11.002

25. Dörr J, Paul F. The transition from first-line to second-line therapy in multiple sclerosis. Curr Treat Options Neurol. 2015;17(6):354. doi:10.1007/s11940-015-0354-5

26. Filippini G, Del Giovane C, Vacchi L, D’Amico R, Di Pietrantonj C, Beecher D. Immunomodulators and immunosuppressants for multiple sclerosis: a network meta-analysis. Cochran Datab Syst Rev. 2013;6:CD008933.. doi:10.1002/14651858.CD008933.pub2

27. Tullman MJ.A review of current and emerging therapeutic strategies in multiple sclerosis. Am J Manag Care. 2013;19(2 Suppl):S21-7.

28. Meyniel C1, Spelman T, Jokubaitis VG, Trojano M, Izquierdo G, Grand'Maison F et al. Country, sex, EDSS change and therapy choice independently predict treatment discontinuation in multiple sclerosis and clinically isolated syndrome. PLoS One. 2012;7(6):e38661. doi:10.1371/journal.pone.0038661 
29. Nicholas R, Straube S, Schmidli H, Pfeiffer S, Friede T. Time-patterns of annualized relapse rates in randomized placebo-controlled clinical trials in relapsing multiple sclerosis: a systematic review and meta-analysis. Mult Scler. 2012;18(9):1290-6. doi:10.1177/1352458511435715

30. Damal K, Stoker E, Foley JF. Optimizing therapeutics in the management of patients with multiple sclerosis: a review of drug efficacy, dosing, and mechanisms of action. Biologics. 2013;7:247-58. doi:10.2147/BTT.S53007
31. Weber MS, Menge T, Lehmann-Horn K, Kronsbein HC, Zettl U, Sellner J et al. Current treatment strategies for multiple sclerosis: efficacy versus neurological adverse effects. Curr Pharm Des. 2012;18(2):209-19. doi:10.2174/138161212799040501

32. Confavreux $\mathrm{C}$, Vukusic $\mathrm{S}$. The clinical course of multiple sclerosis. Handb Clin Neurol. 2014;122:343-69. doi:10.1016/B978-0-444-52001-2.00014-5 